\title{
Avaliação das instituições públicas de ensino superior: direções e interesses subjacentes $^{1}$
}

ZACARIAS GAMA*

\section{RESUMO}

Este texto é produto de uma pesquisa mais ampla que teve como objeto de investigação a autoavaliação de duas universidades públicas, a Universidade do Estado do Rio de Janeiro (UERJ) e a Universidade Federal do Estado do Rio de Janeiro (UNIRIO), realizada por suas Comissóes Próprias de Avaliação (CPAs), em conformidade com a Lei n. 10.861, de 14 de abril de 2004, que instituiu o Sistema Nacional de Avaliação da Educação Superior (Sinaes), e com a Portaria MEC n. 2.051, de 9 de julho de 2004. Objetivou investigar a configuração e a implementação do processo autoavaliativo em ambas as universidades, seu impacto na promoçáo do avanço do

\footnotetext{
${ }^{1}$ Esta pesquisa somente foi possível graças à bolsa do Programa de Incentivo à Produção Científica, Técnica e Artística - Prociência (2006-2009) e ao apoio do Programa de Pós-graduação em Políticas Públicas e Formação Humana (PPFH) da Universidade do Estado do Rio de Janeiro (UERJ). Também contribuíram para a sua realização os seguintes integrantes do Grupo de Pesquisa Políticas Públicas, Avaliação e Gestão da Educação: André Malina, Jorge Oliveira, Paulo Afonso Alves, Luiza Chaves, Vanessa Ramos, Vinicius Calçada, Mariza Gama, Adriano Andrade, Vânia Motta, Marcele dos Prazeres. A responsabilidade pela redação e opinióes é exclusiva de seu autor.

* Professor Adjunto do Departamento de Políticas Públicas, Avaliação e Gestão da Educação (DEPAG) da Faculdade de Educação e da Linha de Pesquisa "Estado e Políticas Públicas" do Programa de Pós-graduação em Políticas Públicas e Formação Humana (PPFH) da Universidade do Estado do Rio de Janeiro (zacarias_gama@yahoo.com.br).
} 
conhecimento e formação de cidadãos, suas contribuiçôes para a superação de reducionismos e explicaçōes simplistas da realidade humana, e suas possíveis contribuiçôes para a construção do diálogo entre as diversas áreas e disciplinas acadêmicas. Entre os seus resultados destacam-se os relatórios estranhados, a subsunção dos tempos livres, o apagamento das subjetividades e a recapacitação das universidades, mediada pela Teoria do Capital Social.

Palavras-chave: Avaliação institucional, Avaliação da educação, Ensino superior, Teoria do capital social.

\section{RESUMEN}

Este texto es el producto de una investigación más amplia que tuvo como objeto de investigación la autoevaluación de dos universidades públicas, la Universidad del Estado de Rio de Janeiro (UERJ) y la Universidad Federal del Estado de Rio de Janeiro (UNIRIO), realizada por sus Comisiones Propias de Evaluación (CPAs), en conformidad con la Ley 10.861, del 14 de abril del 2004, que instituyó el Sistema Nacional de Evaluación de la Educación Superior (Sinaes) y con el decreto del Ministerio de Educación y Cultura (MEC) número 2.051, del 9 de julio del 2004. El objetivo fue investigar la configuración y la implementación del proceso de autoevaluación en ambas universidades, su impacto en la promoción del avance del conocimiento y la formación de ciudadanos, sus contribuciones para la superación de reduccionismos y explicaciones simplistas de la realidad humana y sus posibles contribuciones para la construcción del diálogo entre las diversas áreas y disciplinas académicas. Entre los resultados se destacan los informes estranhados, la subsunción de los tiempos libres, el apagamiento de las subjetividades y la recapacitación de las universidades, mediada por la Teoría del Capital Social.

Palabras clave: Evaluación institucional, Evaluación de la educación, Enseñanza superior, Teoría del capital social.

\section{ABSTRACT}

This text is part of a larger study that had as its object of research the self-assessment of two public universities, the University of Rio de Janeiro (UERJ) and the Federal University of Rio de Janeiro (UNIRIO), through their Own Assessment Committees (CPAs) in accordance with Law Nr. 10,861 of 14 April 2004, which established the National System of Higher Education Assessment (Sinaes) and MEC (Ministry of Education and Cultura) Order Nr. 2051 of July 9, 2004. It investigates the design and implementation of the self-assessment process at both universities, its impact on promoting the advancement of knowledge and on educating citizens, its contributions to overcoming reductionism and simplistic explanations of human reality and its possible contribution to the construction of a dialogue between different areas and academic disciplines. Among the results stand out the estranged reports, the subsumption of leisure time, the suppresion of subjectivity and the requalification of universities, mediated by the Theory of Social Capital.

Keywords: Institutional assessment, Assessment of education, Higher education, Theory of social capital. 


\section{INTRODUÇÃO}

A pesquisa "Avaliação das instituiçóes públicas de ensino superior: direçóes e interesses subjacentes" inscreve-se no âmbito das Políticas Públicas de Avaliação Institucional e desdobra-se como resultado dos estudos e das investigaçóes dos grupos de estudo "Trabalho, Cultura, Conhecimento e Formação Humana" e "Núcleo de Estudos de Políticas Públicas, Avaliação e Gestão da Educação" (NUPAG), ambos vinculados ao Programa de Pós-graduação em Políticas Públicas e Formação Humana (PPFH) da Universidade do Estado do Rio de Janeiro.

Seu objeto de investigação é a autoavaliação de duas universidades públicas, a UERJ e a UNIRIO, por suas Comissóes Próprias de Avaliação (CPAs) em conformidade com a Lei n. 10.861, de 14 de abril de 2004, que instituiu o Sistema Nacional de Avaliação da Educação Superior (Sinaes), e com a Portaria MEC n. 2.051, de 9 de julho de 2004, que regulamenta os procedimentos de avaliação. Nessa lei são claros os objetivos e as finalidades avaliativas: avaliar as IES, seus cursos de graduação e o desempenho acadêmico dos estudantes; melhorar a qualidade da educação superior, expandir sua oferta, aumentar sua eficácia, e aprofundar seus compromissos e responsabilidades sociais, valorizando sua missão, promovendo valores democráticos de respeito à diferença e à diversidade, e afirmando sua autonomia e identidade institucional.

Os pressupostos teóricos e práticos que subjazem ao Sinaes e ao processo autoavaliativo em curso justificam, imediatamente, realizar a abordagem deste objeto com base em um referencial teórico marxista. Mas há também outras razões igualmente importantes.

A primeira, decorre do fato de sabermos que a simples aplicação de uma avaliaçấo construída e ideologicamente difundida como democrática no âmbito da sociedade política náo vem, necessariamente, acompanhada de práticas de democratização e emancipação, bem como também náo é capaz de imprimir, por si só, o caráter democrático e emancipatório à universidade. Nessa perspectiva é que situamos a necessidade de desafiar a lógica implícita nas políticas públicas de avaliação das IES, pois, afinal, não são neutras; elas, normalmente, ocultam significados diversos, produzem sentidos, consolidam valores, afirmam interesses, provocam mudanças, transformam. Mais ainda: constituída como sistema, a avaliação pode ser um poderoso meio com funçóes de contribuir para o metabolismo social do capital que tende a erguer "uma poderosíssima estrutura totalizante de organização e controle do metabolismo societal, à qual todos, inclusive os seres humanos, devem se adaptar" (Antunes, 2006). Assim, considerando a avaliação como "fenômeno essencialmente 
complexo, incompreensível ou até mesmo deturpado", como indica Dias Sobrinho (2002), merece, de fato, toda a nossa atenção, mas desde que afastada de visóes simplificadoras.

Uma segunda razão tem a ver com a ausência de críticas à teoria de avaliação institucional e à sua aplicação. Nossas leituras e investigaçóes indicam que a acelerada vulgarização da teoria de avaliação institucional e sua aplicação por meio de leis não vem sendo acompanhada de análises críticas que captem seu autêntico significado; a avaliação tem sido aceita e aplicada indiscriminadamente como se não houvesse necessidade de apreender e interpretar determinados aspectos e valores que difunde e, tampouco, de ser problematizada e bem compreendida. As intençóes que contém, de igual modo, não foram ainda trazidas à luz, nem a sua especificidade e a forma histórica de sua existência.

Por último, mas não menos importante, a teoria de avaliação institucional, seja em termos amplos, seja em sua aplicação por meio das CPAs, teleologicamente permite a construção de um projeto "ideal" de avaliar a universidade e subordinar sua gestáo às demandas da expansáo do capital, desta vez incorporando o capital humano e o capital social às demais formas pré-existentes. Tal teoria e avaliaçáo, portanto, não tem existência fora das relaçóes sociais capitalistas. Antes revela-se como um projeto conservador, porquanto se objetiva e se exterioriza nos limites deste modo de produção, ainda que usando determinados apelos com força de dissimulação. Seu momento predominante, de fato, não indica ou permite qualquer alusão a rupturas com as relaçôes sociais hegemônicas; antes de propor qualquer negação, a avaliação em curso tão somente apela para novas formas de organização da gestão universitária e do trabalho acadêmico, desta vez fundada em relaçóes de confiança, solidariedade, participação e democracia.

As questôes que nortearam nossas investigaçóes levaram-nos a examinar a configuração e a implementação do processo autoavaliativo em ambas as universidades e o seu impacto na promoção do avanço do conhecimento e da formação de cidadãos, com vistas ao desenvolvimento e ao fortalecimento da sociedade democrática. Queríamos também identificar as contribuiçóes de tal processo avaliativo para a superação de reducionismos e das explicaçóes simplistas da realidade humana, e que elementos ele apresentaria para a construção do diálogo entre as diversas áreas e disciplinas acadêmicas, ultrapassando a construção de agendas individualistas de trabalho e priorizando a dimensão ética das práticas sociais. Para responder a estas questóes foram examinados os documentos oficiais do MEC, os documentos e relatórios produzidos por ambas as CPAs, bem como foram feitas entrevistas com 
professores e funcionários componentes das CPAs. Além disso, foram promovidos dois ciclos de palestras com diversos pesquisadores diretamente envolvidos com os estudos de avaliação institucional e com as comissóes de avaliação das suas instituiçôes de ensino.

A limitação de espaço impede-nos um relato mais denso desta investigação e impóe-nos como objetivo possível a apresentaçáo de alguns resultados, porém destituídos de qualquer pretensão de serem definitivos. A ideia que nos move é a de suscitar o debate e, por conseguinte, submeter nossos resultados à crítica.

\section{RESULTADOS}

Vale ainda ressaltar que nossos resultados, apresentados a seguir e de modo sintético, não esgotam a abordagem do objeto. Temos clareza e conviç̧áo de que eles nos instigam imprimir mais e maior radicalidade à investigação, bem como ao alargamento de sua abrangência.

\section{a) Relatórios estranhados}

A análise dos relatórios finais elaborados pelas CPAs da UERJ e da UNIRIO permite-nos assegurar que eles correspondem às dimensóes avaliativas propostas pelo Sinaes. Claramente, ambas as CPAs restringem-se a tais dimensões com obediência estrita ao que está determinado pela Portaria MEC n. 563, de 21 de fevereiro de 2006 (Brasil, 2006), que aprova, em extrato, o Instrumento de Avaliação de Cursos de Graduação do Sistema Nacional de Avaliação da Educação Superior (Sinaes).

Tais dimensões compóem três categorias de avaliação: 1) organização didáticopedagógica; 2) corpo docente, corpo discente e corpo técnico-administrativo; e 3) instalaçóes físicas, com diferentes pesos: respectivamente 40, 35 e 25. Os grupos de indicadores e indicadores de cada dimensão procuram transparecer de modo quantitativo e qualitativo a situação atual da IES, bem como as suas fragilidades e potencialidades.

A pressuposição subjacente aos relatórios e também aos instrumentos de coleta de dados, é a de haver desarticulaçóes severas no interior das universidades em relação ao PDI e à organização didático-pedagógica. A matriz de tal pressuposto é possível de ser encontrada em diversos documentos oficiais interessados na reforma universitária, incluindo entre eles as Diretrizes Curriculares para os diversos cursos, sobretudo ao considerarem que as universidades têm autonomia para criar, organizar e extinguir cursos e programas, bem como para fixar os seus currículos. Assim, 
cabe-lhes diagnosticar não apenas a articulação das atividades fins com as metas estabelecidas no PDI e com a estrutura curricular, mas também se há separação em cada componente do currículo entre teoria e prática e se há exacerbado formalismo desarticulado da ação.

Observa-se em ambos os relatórios que as pressóes metodológicas, próprias dos instrumentos de coleta de dados, e os possíveis vícios avaliacionais de teor quantitivistas, impregnados nas componentes das CPAs, forçam os relatórios a serem pouco analíticos. É, por exemplo, acentuado neles o desprezo à categoria totalidade e o consequente esclarecimento de que os fatos são integrantes do processo de concretização, como nos indica Kuenzer (2008), que se dá nas IES “através do movimento e das relaçóes que ocorrem das partes para o todo e do todo para as partes". Mesmo quando os relatórios destacam as fragilidades e potencialidades da IES fazem-no de maneira predominantemente técnica. As bases materiais da produção dos elementos indispensáveis aos seus fins últimos - ensino, pesquisa e extensão - sequer são apresentadas conscientemente na relação dialética com a concepção hegemônica de universidade e de trabalho acadêmico que as políticas públicas buscam implantar.

Assim, se por um lado é grande e importante o esforço de dar visibilidade à infraestrutura, isto é, às instalações físicas - bibliotecas, laboratórios e demais instalações específicas das IES, por outro a falta de análise despreza tanto os estudos, como os de Gonçalves e França (2008) por exemplo, que comprovam ter a presença de equipamentos uma influência direta sobre o desempenho acadêmico dos estudantes, como consideraçóes apuradas sobre os recursos financeiros das IES. Estes, entáo, jamais são sequer tangenciados, mesmo quando se sabe que uma simples elevação de $1 \%$ neles é suficiente para elevar o desempenho geral de uma instituição de educação de qualquer nível (Gonçalves e França, 2008; Hedges, Laine e Greenwald, 1994).

O resultado do esforço avaliativo das CPAs é a produção de relatórios estranhados, apesar de toda sedução para incentivar a participação, democracia e solidariedade. Ao invés de se constituírem como estudos de fôlego, capazes de contribuir para a efetiva melhoria das IES, reduzem-se a atender às determinaçóes emanadas do MEC. São elas, afinal, que adquirem toda centralidade nesses relatórios; é o MEC quem usufrui deles para orientar e reorientar as universidades conforme seus propósitos.

\section{b) A subsunção do tempo livre}

A subsunção do tempo livre dos professores e também dos funcionários técnicoadministrativas é um dos resultados desta investigação com capacidade de con- 
firmar outros estudos, tais como os de Mancebo (2006 e 2007), Martins (2005) e Oliveira (2003). No nosso caso, é perceptível ser por meio da avaliação que os indivíduos vão sendo submetidos ao tempo e aos interesses da instituição em regime de monitoramento externo pelo MEC. Quanto mais se consolida e se aperfeiçoa o processo avaliativo e o Plano de Desenvolvimento Institucional tanto mais vai-se liquidando a possibilidade de cada "eu" dedicar-se ao seu próprio tempo de investigação e reflexão. A tendência, tão logo se consolidem os PDIs, é a de que todos interiorizem os mesmos objetivos, metas, cronogramas e "terminem por tornar-se a consciência da instituição" (Stiegler, 2008). Todas as atividades acadêmicas tendem a ser reguladas de modo sincronizado.

A avaliação institucional, na medida em que vai se desenvolvendo e se sofisticando, de fato, tende a hipersincronizar os tempos das consciências individuais, fazendo pontificar o cientificismo, alterar profundamente o ethos da universidade e, ao mesmo tempo, a servir ao processo sociometabólico do capital como excelente instrumento de comparaçáo e categorizaçáo de particularidades esvaziadas e estranhadas. Não por acaso, o MEC, em exposição de motivos que justifica o anteprojeto de Lei da Educação Superior (Brasil, 2007), já convocou as IES a interagir com as suas vocaçóes e as culturas regionais, repartindo o saber e a tecnologia com toda a sociedade. $\mathrm{Na}$ mesma perspectiva, ele entrelaçou avaliação-autonomia-vocação regional ou nacional das IES, admitindo que somente assim é possível, periodicamente, "constatar se as IES, sobretudo as universidades, estão cumprindo, com qualidade, sua missão acadêmica e social” e, em consequência, se elas justificam seus financiamentos públicos ou sua autorização nos termos da lei.

\section{c) Apagamento do indivíduo e da sua subjetividade}

Outro resultado é o gradativo apagamento do indivíduo e da sua subjetividade. No modelo de avaliação institucional em curso o coletivo é. O indivíduo, docente ou funcionário técnico-administrativo, é tido como inconsistente e frágil em seus propósitos particulares e evanescentes, e ainda é capaz de instaurar a dominaçáo caótica do aleatório. $\mathrm{Na}$ perspectiva de tal modelo, a histórica alocação de indivíduos isolados, egoístas, remetidos a si mesmos na universidade apenas cria alguns vínculos institucionais entre eles, pouco ou nada mais que isto. O corolário é a necessidade de superar as diferenças e oposiçóes entre o individual e o coletivo.

A universidade como "comunidade comunicativa", nos moldes em que a teoria avaliacional do Sinaes a compreende, é coletiva, lugar e resultado da comunicação. Mas, deste lugar, entretanto, não se pode e não tem como excluir o protagonismo 
dos comportamentos individuais; o coletivo que se constrói precisa alimentar-se da afluência deles, da participação e empenho, dos seus trabalhos. Pelo menos teoricamente, não há previsão de renúncia à individualidade em termos práticos ou afetivos, considerando-se que a recepção, a elaboração, a participação, etc. encontram-se envolvidas e atravessadas pela dimensão afetiva. $\mathrm{O}$ coletivo surge, entáo, como algo novo e englobante a ser construído, mais concreto e mais rico, para além da simples soma dos elementos singulares envolvidos.

A crítica que o Sinaes faz à atomização dos indivíduos na universidade desconsidera a individualização como um processo que se realiza e se consuma no e pelo viver deveniente, num sistema relacional determinado de sociabilidade, como Marx já antes enunciou. Ela deixa também de examinar as relaçóes e condiçóes em que os indivíduos - os professores e o pessoal técnico-administrativo - se constituem em agentes e interventores na história da própria universidade, assim como as profundas repercussóes das reformas gerenciais efetuadas a partir dos anos 1980 sobre a organização do trabalho docente.

Ao desconsiderar a sociabilidade e a relacionalidade como estruturais e estruturantes, a mesma crítica deixa de examinar a individualizaçáo como produto histórico, a qual, de modo algum ocorre, mesmo com passividade, a despeito do que o Sinaes como reforma de natureza neoliberal pretende. A individualizaçáo que ocorre na universidade é condicionada, e as relaçóes efetivas, não apenas as sociais, mas as econômicas, são em última instância as que são decisivas. É esta reflexão que nos permite afiançar que a pretensão avaliativa em favor de uma "universidade moderna" não está descolada da intenção de favorecer ao capital e à expansão de sua base de dominação. A subsunção dos indivíduos ao coletivo, a partir da mediação feita pelos dispositivos avaliativos referenciados à "verdade social", corresponde a uma modalidade específica de organização do fator subjetivo.

Chama, porém, nossa atenção o desvio que situa o processo avaliativo do Sinaes na contramão das políticas "descoletivizantes" tais como as que foram características bem ao gosto dos liberais-conservadores e conservadores-liberais, em especial quando deixa de propor o desmantelamento de todos os coletivos em favor da individualização das relaçóes de trabalho, do aumento de pressão sobre os docentes e das maiores taxas de sobretrabalho.

\section{d) Recapacitaçáo da Universidade mediada pela Teoria do Capital Social}

Outro resultado importante da investigação está relacionado com a recapacitação da universidade a partir das crises do neoliberalismo cientificista-eficientista. É interessante

40 • Est. Aval. Educ., São Paulo, v. 21, n. 45, p. 33-44, jan./abr. 2010 
observar que os principais teóricos da avaliação institucional, entre eles Dias Sobrinho (2000), fazem contundentes críticas ao neoliberalismo e à avaliação institucional fundada no eficientismo, "defendido como ideologia e financiado por organismos internacionais do Consenso de Washington, sobretudo o FMI e o Banco Mundial”.

Dias Sobrinho, por exemplo, marca com tintas fortes sua insatisfação em face dos graves paradoxos típicos deste "cruzamento de final de século e véspera de um novo milênio", enfatizando que a despeito do espetacular progresso, a miséria, a falta de escrúpulo e a falta de sentido ético do liberalismo capitalista protagonizam "a atual onda de revolução industrial e tecnológica”. O neoliberalismo e a globalização configuram, em sua perspectiva, uma "nova desordem mundial" na qual o mercado tem vantagens como regente da sociedade, favorecendo "descaradamente os países, as corporações e os indivíduos ricos, quando não agentes do crime, aprofundando ainda mais a já muito grave desigualdade de direitos".

Neste mesmo cenário, o mesmo autor diz que o horizonte da equidade social está cada vez mais distante, e ainda se revela como falaciosa a vinculação entre educação e emprego propalada pela Teoria do Capital Humano. Dias Sobrinho reconhece que "educação per se não garante empregos nem consegue criar novas ocupaçóes compatíveis com as demandas", e, com base em Basil Bernstein (1996), indica ser esta vinculação "mais ideológica do que real em seus efeitos, especialmente para os grupos minoritários". O mercado de trabalho, como afirma, não precisa "homogeneamente de tantos novos formandos todos os anos", considerando, inclusive, que a mais alta formação deixou de ser garantia de emprego até nos países mais industrializados. Na América Latina e no Brasil em particular, apesar da expansão das matrículas nas instituiçóes de educação superior, diz ele, os resultados econômicos sáo pífios e é substancial a perda de competitividade em relaçáo ao resto do mundo. Assim, acredita que só a expansão da cobertura náo basta; é preciso aumentar a qualidade educacional e, nomeadamente, a equidade social.

Suas críticas ao neoliberalismo eficientista, se tomadas com imprudência, podem induzir a conclusóes equivocadas, como, por exemplo, a de que está a propor uma ruptura ontológica com o mesmo. Mas quando sáo examinados outros autores que contribuem para fundamentar a teoria de avaliação institucional do Sinaes, é possível constatar que igualmente criticam o neoliberalismo, mas sem propor quaisquer saltos. Todos eles preservam a esfera ontológica em transcurso com as mesmas categorias, legalidade, e relaçóes sociais.

Ontologicamente os autores neoliberais não o renegam e não reivindicam rupturas à sua continuidade de desenvolvimento. Kliksberg (1998), por exemplo, alinhado 
com Putnam (1994), Fukuyama (1999) e Sen (1996), assume "o desenvolvimento do Estado como um processo essencialmente amigável, centrado em ajudar os outros e a si”, bem como em desenvolver novas formas de gerenciamento dos serviços públicos, para que possam conferir às pessoas mais capacidade para se ajudarem mutuamente. Daí é que advém o imperativo de se redesenhar o Estado e redefinir as suas instituiçóes e formas de gestáo, com a adoção de técnicas modernizantes para facilitar e promover o desenvolvimento social.

Os intentos de todos os teóricos convergem exatamente para este ponto, o da nova teoria do capital social. É nele que a avaliação institucional se constitui, então, como poderoso instrumento de intervençáo na gestáo das universidades que, em bases igualmente amigáveis, devem evoluir de modo que se recapacitem para se ajudarem reciprocamente. Eles também se apresentam como discípulos diligentes do Banco Mundial e do BID, porquanto tornam aplicáveis os indicativos contidos em suas respectivas ediçóes: Participation Sourcebook (1996) e no Libro de Consulta sobre Participación (1997). Nestas publicaçóes, a promoção do envolvimento da comunidade em processos de reforma das instituiçóes deve resultar na identificação precisa das suas necessidades prioritárias, na criação de fluxo de informaçóes úteis, na aplicação de ideias inovadoras criadas pela comunidade e na avaliação contínua "do andamento do programa e constituindo ainda um preventivo quase não-superável diante da possibilidade de corrupção” (apud Kliksberg, 1998).

\section{CONSIDERAÇÕES FINAIS}

As questóes que nortearam nossas investigaçóes indiscutivelmente levaramnos a examinar a configuração, a implementação e os relatórios finais do processo autoavaliativo de ambas as universidades. Por mais que as tivéssemos como norte, foi impossível aquilatar quaisquer impactos na promoção do avanço do conhecimento e formação de cidadáos, contribuiçóes para a superaçáo de reducionismos e explicaçôes simplistas da realidade humana, e o mesmo em relação à construção do diálogo entre as diversas áreas e disciplinas acadêmicas de forma que ultrapasse a construção de agendas individualistas de trabalho e priorizar a dimensão ética das práticas sociais.

Conforme nossas investigaçóes, foi possível constatar que a avaliação institucional tende gradualmente a enclausurar as universidades mesmo que a considerem um sistema aberto, dinâmico e dialético. Instituída como sistema, a avaliação deve ir se impondo por meio do jogo das regulaçóes e das autorregulaçóes de modo constringente em favor dos interesses subjacentes às políticas de governo e de Estado,

42 - Est. Aval. Educ., São Paulo, v. 21, n. 45, p. 33-44, jan./abr. 2010 
a serviço do processo sociometabólico do capital. A avaliação, todavia, em nível teórico e prático, é pensada de modo que se apresente dissimuladamente como democrática, participativa e capaz de criar redes interpessoais de solidariedade, e de estar comprometida com a construção voluntária de uma "universidade moderna" sempre referenciada a critérios de "verdade social".

Ficou claro que todo o pressuposto ontológico contido na avaliação institucional converge, porém, para a contradição antes explicitada por Engels (1976). Ao situar os sujeitos dentro de seus limites não se importa que tenham conhecimento exaustivo do sistema-aberto-universidade na sua conexão total, porque como docentes e técnico-administrativos nunca poderão resolver completamente a complexidade sistêmica, quer por sua própria natureza humana, quer pela do sistema do mundo. As alternativas teóricas e práticas propostas por esta avaliação apresentam-se, então, com claros intentos metódicos e também ideológicos de regulação e autorregulação, arrogando para si a sobrevalorização da avaliação, das suas dimensôes e categorias, nomeadamente no que diz respeito ao seu poder determinante, ao seu alcance na transformação prática do real e, sobretudo, no apagamento do indivíduo e da sua subjetividade ao subsumi-los aos cânones essenciais do desenvolvimento institucional.

A pesquisa, como avanço teórico, permitiu ainda desvelar os intentos de reconversão das instituiçóes sociais, em particular, e do Estado neoliberal, em geral, a partir de processos de desenvolvimento de novas formas de gerenciamento dos serviços públicos para que possam conferir às pessoas mais capacidade para ajudar a si próprias e os outros. A expectativa mais recorrente é que todas se tornem produtoras de capital social. Neste cenário, mediado pela Teoria do Capital Social, a avaliação institucional constitui-se, então, em poderoso instrumento de intervenção na gestão das universidades que, em bases igualmente amigáveis e com a solidariedade, confiança e a participação de todos, devem idealmente evoluir.

Como última consideração, vale acentuar a existência de uma profunda alteração do processo autoavaliativo. O MEC mudou seu direcionamento ao criar um sistema eletrônico (e-MEC) de fluxo de trabalho e gerenciamento de informaçóes relativas aos processos de regulação da educação superior no sistema federal de educação por meio da Portaria Normativa n. 40, de 12 de dezembro de 2007, determinando que ao final de cada ciclo do Enade - três anos - seja feita uma qualificação das universidades, acrescida dos dados do Censo do Ensino Superior, das condiçôes dos laboratórios e bibliotecas, etc. Conforme esse novo procedimento somente as universidades com qualificação igual a 01 ou 02 serão objeto de avaliaçóes externas. 


\section{REFERÊNCIAS BIBLIOGRÁFICAS}

ANTUNES, R. Os Sentidos do trabalho: ensaio sobre a afirmação e negação do trabalho. São Paulo: Boitempo, 2006.

BERNSTEIN, B. A Estruturação do discurso pedagógico: classe, códigos e controle. Petrópolis: Vozes, 1996.

BID. Libro de Consulta sobre Participación. Washington: BID, 1997.

BRASIL. Ministério da Educação. Exposição de motivos: Anteprojeto de Lei da Educação Superior. Brasília: MEC, 2007. Disponível em: http://portal.mec.gov.br/arquivos/pdf/ anteprojeto.pdf. Acesso em: dez. 2007.

. Ministério da Educação. Portaria MEC n. ${ }^{\circ}$ 563, de 21 de fevereiro de 2006. Brasília: MEC, 2006.

DIAS SOBRINHO, J. Avaliação da Educação Superior. Petrópolis: Vozes, 2000

. Educação e avaliação: técnica

e ética. In: DIAS SOBRINHO, J.; RISTOFF, D. I. Avaliação democrática: para uma universidade cidadã. Florianópolis: Insular, 2002.

ENGELS, F. Anti-Duhring. Rio de Janeiro: Paz e Terra, 1976.

FUKUYAMA, F. Social capital and civil society. FMI Conference prepared for delivery at the IMF Conference on Second Generation Reforms, 1999. Disponível em: http://www.imf. org/external/pubs/ft/seminar/1999/reforms/ fukuyama.html. Acesso em: fev. 2009.

GONÇALVES, F. O.; FRANÇA, M. T. A. Transmissão intergeracional de desigualdade e qualidade educacional: avaliando o sistema educacional brasileiro a partir do Saeb 2003. Ensaio: Avaliação e Políticas Públicas em Educação, Rio de Janeiro, v. 16, n. 61. p. 639-662, out./dez. 2008.

HEDGES, L.; LAINE, R. D.; GREENWALD, R. Does money matter? Meta-analysis of the effects of differential schools inputs on student outcomes. Educational Reseachers, Washington, v. 23, n.3, p. 5-14, apr. 1994.

KLIKSBERG, Bernardo. Repensando el Estado para el desarrollo social: mas allá de dogmas y convencionalismos. São Paulo: Cortez, 1998.

KUENZER, Acácia Zeneida. Desafios teóricometodológicos da relação trabalho-educação e o papel social da escola. In: FRIGOTTO, Gaudêncio (Org.) Educação e crise do trabalho: perspectivas de final de século. Petrópolis: Vozes, 2008, p.55-75.

MANCEBO, D. Em discussão o trabalho docente. Estudos e Pesquisas em Psicologia, Rio de Janeiro, v. 6, n.1, 2006.

Trabalho docente: subjetividade

e sobreimplicação. Reflexão \& Crítica, Porto Alegre, v. 20, n. 1, 2007.

MARTINS, L. S. Os "sentidos do trabalho" docente universitário em tempos neoliberais. Revista da UFG, Goiânia, v. 7, n. 2, dez. 2005.

OLIVEIRA, D. As Reformas educacionais e suas repercussões sobre o trabalho docente. In: OLIVEIRA, D. (Org.). Reformas educacionais na América Latina e os trabalhadores docentes. Belo Horizonte: Autêntica, 2003. p. 13-38.

PUTNAM, R. D. Para hacer que la democracia funcione. Caracas: Galac, 1994.

SEN, A. Development thinking at the beginning of the 21st century. In: BID. Development thinking and practice conference. Washington, set. 1996.

STIEGLER, B. A Hipermassificação e a destruição do indivíduo. Rio de Janeiro: Le Monde Diplomatique, fev. 2008, p. 34.

WORLD BANK. The World Bank participation sourcebook. Washington: WB, 1996.

Recebido em: maio 2009

Aprovado para publicaçáo em: março 2010

44 - Est. Aval. Educ., São Paulo, v. 21, n. 45, p. 33-44, jan./abr. 2010 